\title{
Effects of dietary plant-derived phytonutrients on the genome-wide profiles and coccidiosis resistance in the broiler chickens
}

\author{
Hyun S Lillehoj ${ }^{j^{*}}$, Duk K Kim', David M Bravo², Sung H Lee \\ From International Symposium on Animal Genomics for Animal Health (AGAH 2010) \\ Paris, France. 31 May - 2 June 2010
}

\begin{abstract}
Background: The present study was conducted to investigate the effects of dietary plant-derived phytonutrients, carvacrol, cinnamaldehyde and Capsicum oleoresin, on the translational regulation of genes associated with immunology, physiology and metabolism using high-throughput microarray analysis and in vivo disease challenge model of avian coccidiosis.

Methods: In this study, we used nutrigenomics technology to investigate the molecular and genetic mechanisms of dietary modulation of host innate immunity and metabolism by three phytonutrients. To validate their immunomodulatory effects in a disease model, young broiler chickens fed a standard diet supplemented with three phytochemicals (carvacrol, cinnamaldehyde, and Capsicum oleoresin) from one day post-hatch were orally challenged with E. acervulina. The body weight gain and fecal oocyst production were used to evaluate coccidiosis disease parameters.

Results: Analysis of global gene expression profiles of intestinal tissues from phytonutrient-fed birds indicated that Capsicum oleoresin induced the most gene changes compared to the control group where many of these genes were associated with those of metabolism and immunity. The most reliable network induced by dietary cinnamaldehyde treatment was related with the functions of antigen presentation, humoral immune response, and inflammatory disease. Furthermore, dietary supplementation with these phytonutrients significantly protected broiler chickens against live coccidiosis challenge infection based on body weight and parasite fecundity.

Conclusions: The results of this study provide clear evidence to support the idea that plant-derived phytochemicals possess immune-enhancing properties in chickens and these new findings create a new possibility to develop effective drug-free alternative strategies for disease control for poultry infectious diseases.
\end{abstract}

\section{Background}

In view of rising concerns on the extensive use of antibiotics in animal production, there is an increasing interest for developing alternative disease control strategy to enhance animal health and to reduce the use of antimicrobials. One promising new possibility to achieve this goal is the use of natural foods and herbal products

\footnotetext{
* Correspondence: Hyun.Lillehoj@ars.usda.gov

'Animal Parasitic Diseases Laboratory, Animal and Natural Resources Institute, United States Department of Agriculture-Agricultural Research Service, Beltsville, MD 20705, USA

Full list of author information is available at the end of the article
}

to enhance feed efficiency, gut health, and innate immunity [1]. In clinical medicine, plant-derived products are increasingly being used as feed supplements to enhance immunity to diseases and cancers. Among these products, the dietary effects of the mixture of three plantderived phytochemicals, carvacrol, cinnamaldehyde, and Capsicum oleoresin as anti-bacterial and anti-fungal agents have been reported [2]. Carvacrol is a component of numerous aromatic plants, such as Origanum vulgare, thyme, and wild bergamot [3]. The anti-microbial functions of these herbs are associated with carvacrol $[4,5]$ since carvacrol vapour has been shown to inhibit

\section{Biomed Central}

(C) 2011 Lillehoj et al; licensee BioMed Central Ltd. This is an open access article distributed under the terms of the Creative Commons Attribution License (http://creativecommons.org/licenses/by/2.0), which permits unrestricted use, distribution, and reproduction in any medium, provided the original work is properly cited. 
Salmonella growth in chickens [6]. Cinnamaldehyde is a constituent of cinnamon and widely applied as flavoring. It has been proven to have strong anti-bacterial activity against Escherichia coli, Pseudomonas aeruginosa, Enterococcus faecalis, Staphylococcus aureus, Staphylococcus epidermidis, methicillin-resistant Staphylococcus aureus (MRSA), Klebsiella pneumoniae, Salmonella sp., and Vibrio parahemolyticus[7]. Hot pepper (Capsicum spp.) is vegetable of importance in human nutrition and has many beneficial effects on human health $[8,9]$. Capsicum oleoresin, prepared by organic extraction of pepper fruits, contains anti-bacterial activity and is effective in treating stomach illnesses (Spices board, 2008). It contains the pungent principles, capsicin which has effects on the resistance to Salmonella enteritidis infection by altering $\mathrm{pH}$ and histological changes $[10,11]$. However, there is very limited information on the use of phytonutrients in veterinary medicine, and almost no knowledge on the underlying immunomodulation mechanism mediated by dietary phytonutrients in poultry.

With emerging "omics" technology, scientists are now better able to investigate how dietary food components can affect physiological functions and the underlying cellular and molecular mechanisms. Nutrition-related genomics technology has revolutionized the field of nutrition and two similar and yet distinct disciplines related to nutrition genomics have evolved, "nutrigenetics" and "nutrigenomics" [12]. In particular, the emerging field of functional nutritional genomics has provided unprecedented opportunities for increasing our understanding of how nutrients modulate gene and protein expression to influence cellular metabolism [12]. When integrated with other "omics" technologies in a systems biology approach, novel nutrition-based intervention strategies are expected to provide an effective alternative disease control strategy for agricultural animal industry.

In this study, we used three immunologically active phytochemicals (carvacrol, cinnamaldehyde and Capsicum oleoresin) to investigate the underlying molecular mechanisms of nutrition-mediated immunomodulation of host innate immunity and to validate their health promoting effects using an in vivo coccidiosis disease challenge model.

\section{Results}

In the present study, we analyzed transcriptional profiles using the avian intestinal intraepithelial lymphocyte microarray (AVIELA) consisted of 10,162 spots. The total number of IEL elements which were significantly altered ( $>2.0$ fold) in the expression levels by three different phytonutrients (carvacrol, cinnamaldehyde, and Capsicum oleoresin) were 74, 62, and 254, respectively.
To confirm the results of microarray analysis, we selected five genes and followed the kinetics of their corresponding transcript levels following dietary supplementation with Capsicum oleoresin. All of the selected genes showed $>2.0$-fold altered expression in the normalized AVIELA data $(P<0.05)$. Of these, two (CD74 and $\mathrm{CDC5L}$ ) were associated with the first network and another two (UBE31 and FADD) were included in the second network of pathway analysis. As shown in Figure 1 , the transcriptional changes in these genes as assessed by qRT-PCR showed similar patterns when compared with the original microarray data.

Pathway and gene network analysis using IPA software showed that Capsicum oleoresin and cinnamaldehyde significantly modified the pathways related with carbohydrate metabolism (Figure $2 \mathrm{~A}$ ) such as the citrate cycle ( $P$ values: $1.95 \times 10^{-4}$, and $8.91 \times 10^{-4}$, respectively), and glyoxylate and dicarboxylate metabolism ( $P$ values: 2.14 $\mathrm{x} 10^{-2}$, and $1.82 \times 10^{-2}$, respectively). The pathway for glycolysis/gluconeogenesis was induced by Capsicum oleoresin ( $P$ value: $\left.4.07 \times 10^{-2}\right)$. However, in lipid metabolism, only carvacrol treatment showed statistically significant changes associated with androgen and estrogen metabolism ( $P$ value: $\left.9.55 \times 10^{-3}\right)$ and linoleic acid metabolism ( $P$ value: $\left.4.79 \times 10^{-2}\right)$ pathways (Figure $2 \mathrm{~B}$ ).

IPA network analysis revealed that 7, 9, and 17 biologically relevant networks were associated with cinnamaldehyde, carvacrol, and Capsicum oleoresin groups, respectively. Among the networks, the three most reliable ones from each treatment were displayed in Table 1. Top functions represent the top 3 high-level functions

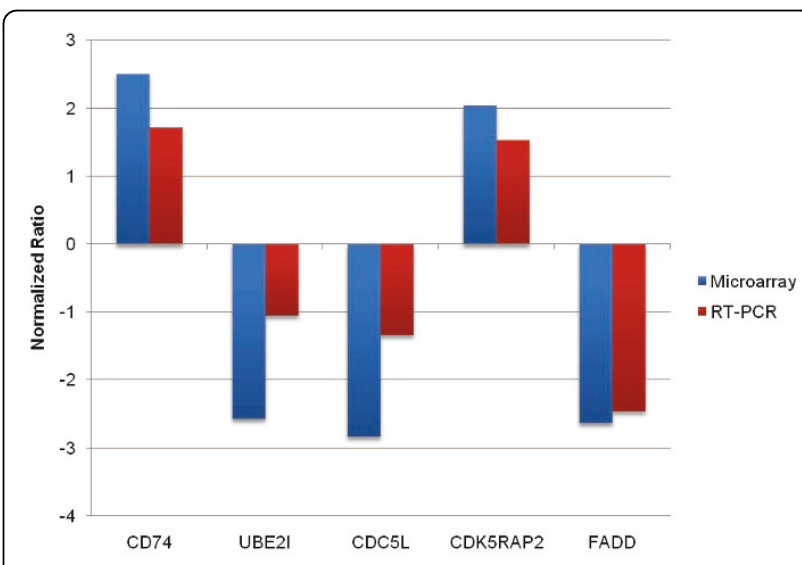

Figure 1 Comparison between the expression levels of selected genes from microarray analysis and quantitative realtime PCR following dietary supplementation with Capsicum oleoresin. CD74 molecule (CD74); ubiquitin-conjugating enzyme E2I (UBE2I); CDC5 cell division cycle 5-like (CDC5L); CDK5 regulatory subunit associated protein 2 (CDK5RAP2); Fas (TNFRSF6)-associated via death domain (FADD). 

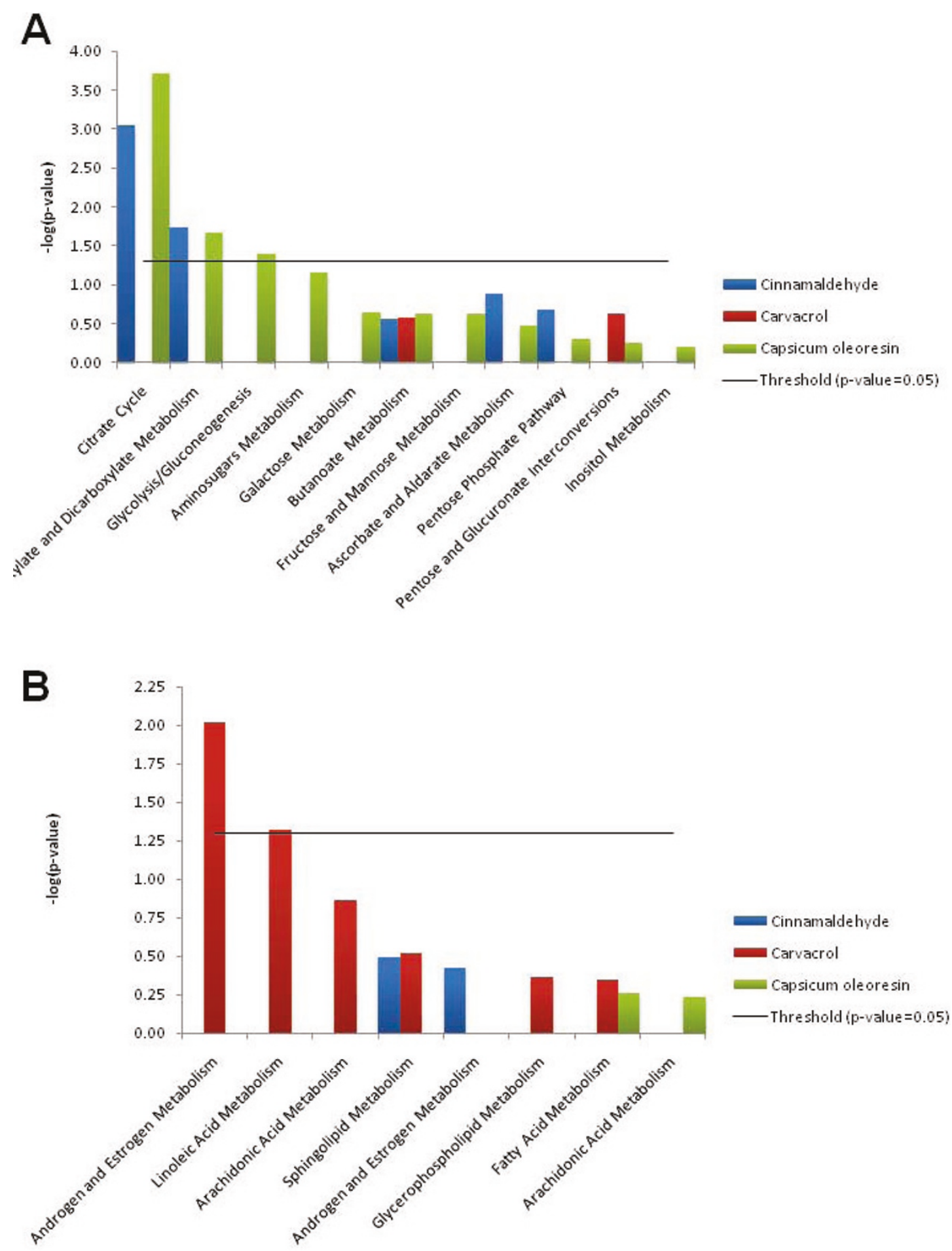

Figure 2 Canonical Pathway analysis of differential expressed genes by the feeding of three different phytonutrients. Datasets were analyzed by the Ingenuity Pathways Analysis software. The significance is expressed as a $P$ value that is calculated using the right-tailed Fisher's exact test. (A) The comparison of the pathways related with (A) carbohydrate metabolism and (B) lipid metabolism. Threshold: $P$ value $=0.05$. 
Table 1 Three most reliable gene networks associated with each phytonutrient

\begin{tabular}{|c|c|c|c|c|}
\hline Treatment & $\begin{array}{l}\text { Network } \\
\text { No. }\end{array}$ & Top Functions* & $\begin{array}{l}\text { Focus } \\
\text { Genes }\end{array}$ & Score \\
\hline & 1 & Antigen Presentation, Humoral Immune Response, Inflammatory Disease & 18 & 39 \\
\hline \multirow[t]{3}{*}{ Cinnamaldehyde } & 2 & Cardiovascular System Development and Function, Tissue Morphology, Drug Metabolism & 14 & 28 \\
\hline & 3 & Cell Death, Gene Expression, Cellular Development & 14 & 27 \\
\hline & 1 & Cell Morphology, Cellular Assembly and Organization, Cellular Function and Maintenance & 14 & 29 \\
\hline \multirow[t]{3}{*}{ Carvacrol } & 2 & Cell-To-Cell Signaling and Interaction, Tissue Development, Cellular Movement & 12 & 24 \\
\hline & 3 & Genetic Disorder, Renal and Urological Disease, Endocrine System Development and Function & 12 & 24 \\
\hline & 1 & $\begin{array}{l}\text { Gene Expression, Cardiovascular System Development and Function, Cellular Growth and } \\
\text { Proliferation }\end{array}$ & 23 & 39 \\
\hline \multirow{2}{*}{$\begin{array}{l}\text { Capsicum } \\
\text { oleoresin }\end{array}$} & 2 & Developmental Disorder, Genetic Disorder, Neurological Disease & 19 & 28 \\
\hline & 3 & $\begin{array}{l}\text { Carbohydrate Metabolism, Cardiovascular System Development and Function, Hepatic System } \\
\text { Disease }\end{array}$ & 15 & 23 \\
\hline
\end{tabular}

* The top 3 high-level functions from the Functional Analysis of a Network. This provides an overview of the biological functions associated with a given network.

from the Functional Analysis of a Network which represents an overview of the biological functions associated with a given network. Figure 3 describes the first network from the treatment group of cinnamaldehyde. This network includes 18 focus genes related to the functions of antigen presentation, humoral immune response, and inflammatory disease. All relationships between genes in the network are graphically represented as lines and nodes are displayed using various shapes representing the functional class of the gene product. These relationships are supported by at least one literature reference or from canonical information stored in the Ingenuity Knowledge Base.

To further validate biological functions of carvacrol, cinnamaldehyde, and Capsicum oleoresin in a poultry infectious disease model, broiler birds fed with standard diet supplemented with the plant extract mix designated as XT6930 $(5 \mathrm{mg} / \mathrm{kg}$ of carvacrol, $3 \mathrm{mg} / \mathrm{kg}$ of cinnamaldehyde, and $2 \mathrm{mg} / \mathrm{kg}$ of Capsicum oleoresin) were orally challenged with E. acervulina. Feeding with XT6930 significantly enhanced body weight gains and reduced gut lesions of E. acervulina-infected chickens (Figure 4). Furthermore, broiler chickens which were continuously fed with a standard diet supplemented with carvacrol, cinnamaldehyde and Capsicum oleoresin from hatch showed significantly reduced gut lesions and lower proinflammatory cytokine gene expression (data not shown) post challenge infection with $E$. acervulina compared to the controls fed only the standard diet.

\section{Conclusions}

This study demonstrates that dietary immunomodulation mediated by the combination of carvacrol, cinnamaldehyde and Capsicum oleoresin enhanced coccidiosis resistance. Microarray analysis indicated that these phytonutrients mediated transcriptional changes associated with metabolism and cell-mediated immunity which were reflected by enhanced protective immune response to avian coccidiosis. In general, Capsicum oleoresin induced most change of gene expression on AVIELA compared to the two other nutrients studied in this work.

Transcriptional profiling and pathway analysis revealed differential expression by the three dietary phytonutrients. The pathway analysis determined that lipid metabolism, linoleic acid metabolism and androgen and estrogen metabolism were regulated by carvacrol in this study. Carvacrol has well-known antibacterial and antifungal properties as well as antioxidant effects, with clinical applications for topical treatment of mucosal and epithelial infection $[13,14]$. In broiler meat, feed supplement with carvacrol was found to delay lipid oxidation after 5 and 10 days of storage [15]. Carvacrol inhibited the linoleic acid peroxidation as the same level as the positive control [16], influenced lipid metabolism and down-regulated the expression of oxidative stress markers such as CYP1A1 (cytochrome P450, family 1, subfamily A, polypeptide 1) [17].

In previous studies, supplementation with carvacrol, cinnamaldehyde, and Capsicum did not show any influence on body weights or feed efficiency, but improved ileal and fecal digestibility in homeostatic status in chickens $[2,11,18]$. However, in this study, dietary feeding of young broiler chickens with these nutrients improved body weight gain and reduced oocyst shedding in the diseased chickens. The detailed mechanisms are not known but may involve morphological modification of cells of the gastrointestinal mucosa [19] and genetic regulation of metabolic network. In our previous results [20], several immunerelated genes showed changes following treatment with 
phytonutrients reflecting their well known medicinal effects against various bacteria or fungi in chicken infection studies $[6,10,19]$. Considering these observation, the phytonutrients used in this study have shown beneficial effects on host immune system and metabolic conditions through the regulation of gene expression in the chicken gut. Therefore, these nutrients have potentials to be the alternatives of antibiotics in poultry feed.

In the present study, the most reliable network of cinnamaldehyde treatment was determined as the functions of antigen presentation, humoral immune response, and inflammatory disease. Cinnamaldehyde has been known with its anti-inflammatory and anti-cancer effects $[20,21]$. In our previous study, the regulatory effects of cinnamaldehyde on inflammatory responses involved suppression of nitric oxide (NO) production, up-regulation of co-stimulatory molecules (CD80 and CD69) and proinflammatory cytokines such as TNF- $\alpha$ and IL- $1 \beta$ [22]. Among the focus gene including the first network altered by cinnamaldehyde treatment, CD2 which is a $\mathrm{T}$ and NK cell surface protein that mediates low affinity cell-cell interactions by binding to related immunoglobulin superfamily (IgSF) proteins, CD58 in humans and CD48 in rodents, was down-regulated [23]. Soluble DPP4 (dipeptidy l-peptidase 4) was reported to induce T cell proliferation in antigen presenting cells [24] and Hsp90b1 (heat shock protein 90, beta (Grp94), member $1)$ activates the release of nitric oxide by antigen presenting cells [25].

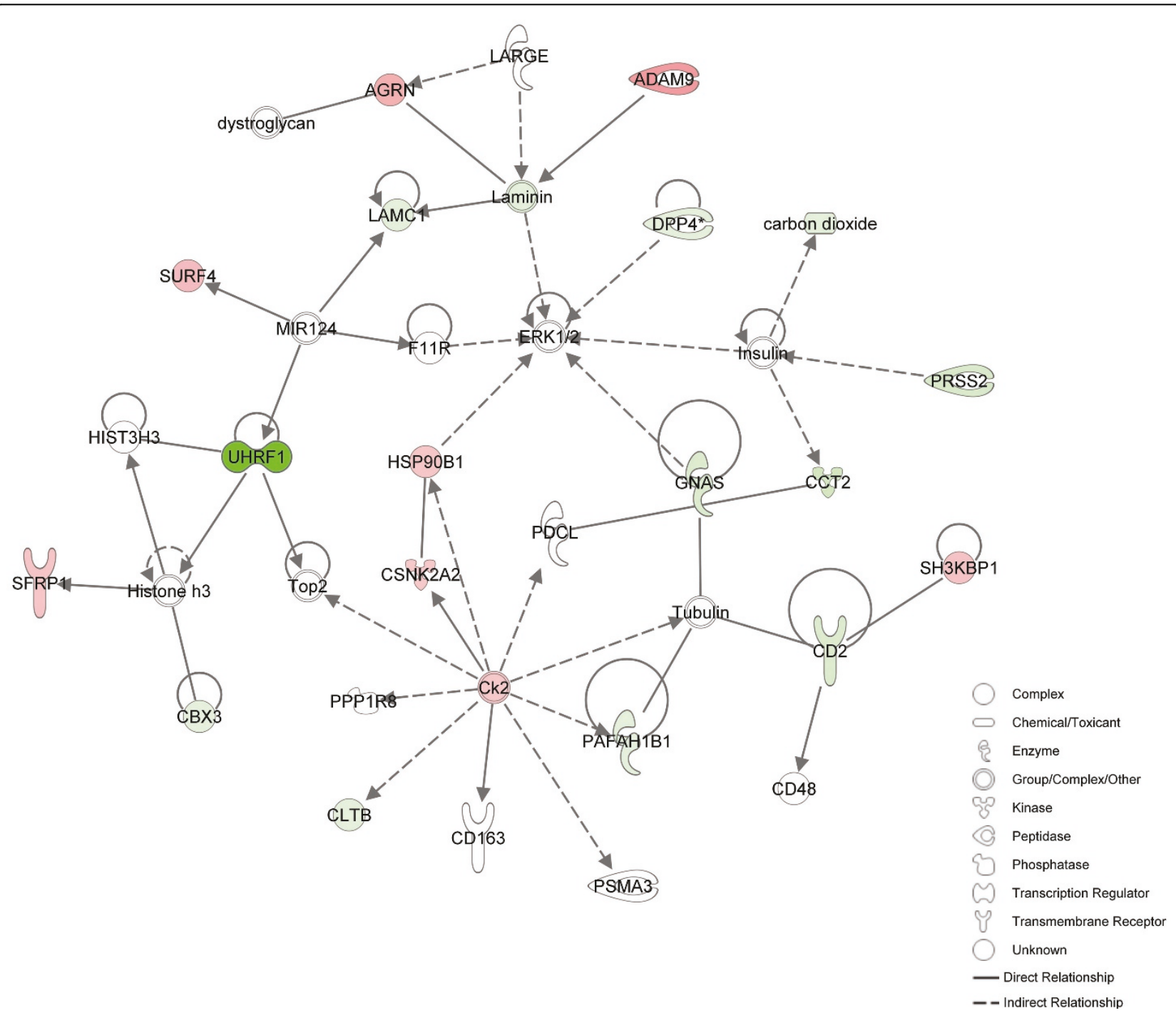

Figure 3 The most reliable network of genes exhibiting $\mathbf{2}$. 0 -fold expression induced by cinnamaldehyde treatment. Top functions of this network are Antigen presentation, Humoral immune response and Inflammatory disease. Up- and down-regulated genes are illustrated with red and green colors, respectively. The intensity of each gene indicates the expression level of the genes. 


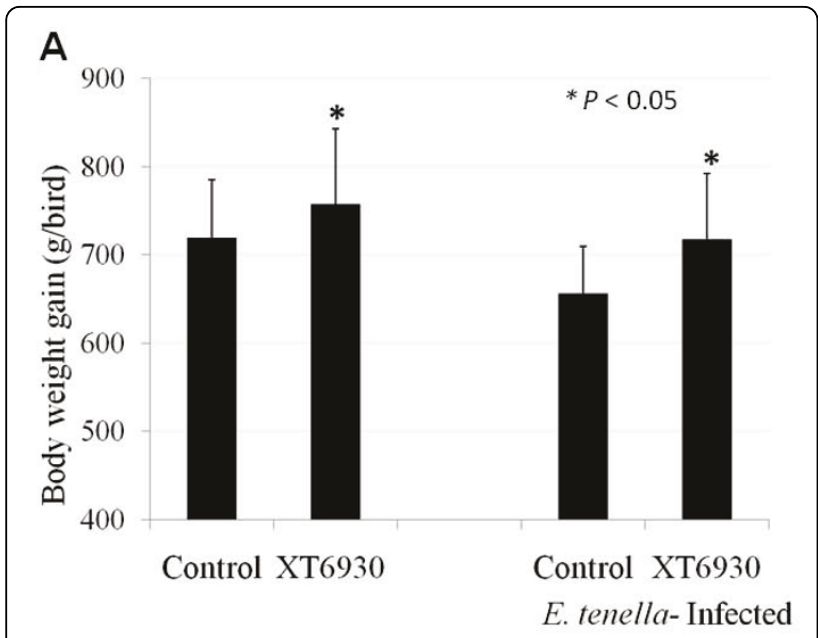

B

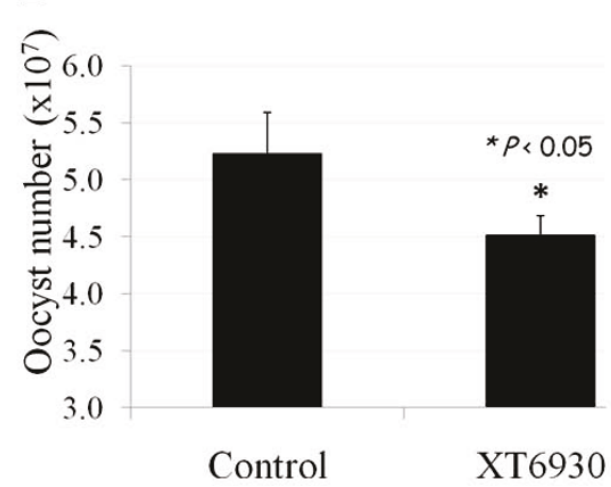

Figure 4 Body weight gains (A) and total fecal oocyst output (B) of broiler birds fed with diet containing XT6930 $(5 \mathrm{mg} / \mathrm{kg}$ of carvacrol, $3 \mathrm{mg} / \mathrm{kg}$ of cinnamaldehyde, $2 \mathrm{mg} / \mathrm{kg}$ of Capsicum) post $E$. acervulina infection. Body weights were measured at 0 and 9 days post E. acervulina infection. Fecal oocyst outputs were collected during the 6-9 days post-infection period. ${ }^{*} P<0.05$.

In conclusion, genome-wide profiling revealed differential expression by three dietary phytonutrients and bioinfomatical analysis identified the pathways and networks of genes induced by carvacrol, cinnamaldehyde and Capsicum oleoresin. These results provide new information concerning the molecular mechanisms involved in dietary modulation in the chicken gut and will facilitate the development of novel dietary strategies to enhance poultry health. Furthermore, for complex intestinal parasitic infection such as coccidiosis whose treatment has traditionally relied upon prophylactic medication, dietary immune enhancement using edible plants provides a safe alternative control method to reduce economic losses. With rapidly developing genomics technology, systems and network biology will play an important role to increase our understanding of how nutrition influences metabolic and immunity pathways and enhances animal health and well-being. Agricultural animal scientists should quickly adopt rapidly developing technologies to understand the underlying mechanism of nutrition-mediated immunomodulation and to develop novel dietary intervention strategies to achieve sustainable agriculture and to minimize the use of antibiotics in animal production. Furthermore, systems biology should be applied to investigate to what extent individual genetic variations affect animal's response to nutrition and other environmental stress [26].

\section{Methods}

Experimental birds, diets and disease challenge

One-day-old broilers (Ross/Ross, Longenecker's Hatchery, Elizabethtown, PA) were randomly assigned to 4 groups (20 birds per group). The proportions of carvacrol, cinnamaldehyde, and Capsicum oleoresin in feed were based on the optimal doses from our pretrial experiments [22]. Chickens were fed for 7 days beginning from hatch with a standard diet alone (control) or with diets supplemented with carvacrol $(5.0 \mathrm{mg} / \mathrm{kg})$, cinnamaldehyde $(3.0 \mathrm{mg} / \mathrm{kg})$, or Capsicum oleoresin $(2.0$ $\mathrm{mg} / \mathrm{kg})$. At 14 day post-hatch $(\mathrm{dph})$, all birds except uninfected control were orally infected with $2.0 \times 10^{4}$ sporulated oocysts of Eimeria acervulina (E. acervulina). Body weights of chickens were measured at 0 and 10 days post-infection (dpi) as described [22].

\section{Quantitative RT-PCR (qRT-PCR)}

Intestinal duodenum tissues were obtained from uninfected chickens (for microarray studies) at day $14 \mathrm{dph}$ (4 birds/ group). To validate the microarray data, we selected 5 genes and determined the expression levels by qRT-PCR as previously described $[27,28]$. Total RNA was extracted using TRIzol (Invitrogen, Carlsbad, CA) and qRT-PCR oligonucleotide primers for chicken cytokines and the GAPDH internal control as previously described were used $[27,28]$.

\section{RNA extraction and aminoallyl-labeled RNA preparation}

Intestinal intraepithelial lymphocytes (IELs) were isolated by Percoll density gradient centrifugation as described previously [1]. Total RNA was isolated from pooled IELs from each treatment group using Trizol and aminoallyl-labeled RNA was prepared using the Amino Allyl Message Amp II aRNA Amplification Kit (Ambion, Austin, TX) according to the instruction of the manufacturer. Two 20- $\mu$ g aliquots of each aminoallyl-RNA sample were fluorescently labeled with AlexaFluor 555 or AlexaFluor 647 (Invitrogen) and labeled RNA were column-purified using the RNA Amplification Kit (Ambion). The RNA concentrations and labeling efficiencies were determined spectrophotometrically. 


\section{Mircroarray hybridization, scanning and image analysis} The avian IEL array (AVIELA) consisted of 10,162 spots representing elements from 3 sources: 1) cDNA from chicken IELs [29], 2) immune-related cDNA from the lipopolysaccharide-activated HD11 macrophage cell line [30], and 3) direct PCR clones of selected chicken cytokines and chemokines [29]. Each element was duplicated on the array slide. According to a reference design with dye swap [31], 4 values were obtained for each treatment. Hybridizations were performed using HybIt hybridization buffer (TeleChem, Sunnyvale, CA) in ArrayIt reaction cassettes at $50^{\circ} \mathrm{C}$ overnight as described [32]. Each sample had a repeated hybridization using the alternate fluorescent dye between the treatment and control. Images were acquired by laser confocal scanning using a ScanArray Lite microarray analysis system (Perkin-Elmer, Boston, MA) at a resolution of $10 \mu \mathrm{m}$. A 16-bit TIFF image was generated for each channel corresponding to the AlexaFluor 555 and AlexaFluor 647 dyes. The scanned microarray images for each channel were overlaid and fluorescent intensities were quantified using ScanArray Express 3.0 software (Perkin-Elmer). Spots were detected using an adaptive circle algorithm in the ScanArray program and all spots were visually confirmed.

\section{Microarray and bioinformatics data analysis}

GeneSpring GX10 software (Silicon Genetics, Redwood, CA) was used to qualify and normalize image analysis data and to perform the fold-change analyses as described [32]. To generate signal ratios, signal channel values (treatment group) were divided by control channel values (control group). The significantly differentially expressed genes were filtered using the volcano plot built by comparing the treatment of each phytonutrient with itself at the false discovery rate $(F D R)<0.1$. The modulated elements were defined by 2 -fold differences and a cutoff of $P<0.05$ by parametric test. The microarray information has been submitted online into the Minimum Information About a Microarray Experiment (http://www.mged.org/Workgroups/MIAME). The accession number for this study is E-MEXP-2204. IEL cDNA elements which were used to create the IEL cDNA microarray were mapped to the chicken genome reference assembly (version 2.1) and reference RNA and protein sequences (formatted database for Blast, December 2007) using National Center for Bioinformatics Institute (NCBI) Blast (version 2.2.13). To analyze pathway information, chicken Entrez gene identifications wer mapped to Homologen IDs (locus link IDs) for human genes because a large portion of these sequences have not been defined in chicken.

The genes which were differentially expressed by treatments were analyzed by the Ingenuity Pathway
Analysis (IPA) software (Ingenuity Systems, Inc. Redwood City, CA). Each identifier was mapped to its corresponding gene object in the Ingenuity Knowledge Base. Both 2.0-fold up- and down-regulated identifiers were defined as value parameters for the analysis. These genes, called focus genes, were overlaid onto a global molecular network developed from information contained in the Ingenuity Knowledge Base. The functional analysis was performed to identify the biological functions, canonical pathways and the network of genes from the datasets that were mapped with the Ingenuity Pathways Knowledge Base. Fischer's exact test was used to calculate a $P$ value determining the probability that each biological function, pathway, and network assigned to that dataset was due to chance alone. Networks of focus genes were algorithmically generated based on their connectivity.

\section{Statistical analyses}

Statistical analyses were performed using SPSS software (SPSS $15.0 \mathrm{~K}$ for Windows, Chicago, IL), and all data were expressed as means \pm SEM values. Comparisons of the mean values were performed by one-way analysis of variance, followed by the multiple Duncan test and differences were considered statistically significant at $P<$ 0.05 .

\section{Acknowledgements}

This project was partially supported by a Trust agreement established between ARS-USDA and Pancosma. All purified plant extracts used in this study was provided by Pancosma, S.A.

This article has been published as part of BMC Proceedings Volume 5 Supplement 4, 2011: Proceedings of the International Symposium on Animal Genomics for Animal Health (AGAH 2010). The full contents of the supplement are available online at http://www.biomedcentral.com/1753$6561 / 5$ ? issue $=\$ 4$

\section{Author details}

'Animal Parasitic Diseases Laboratory, Animal and Natural Resources Institute, United States Department of Agriculture-Agricultural Research Service, Beltsville, MD 20705, USA. ²Pancosma S.A., Voie-des-Traz 6, CH-1218 Le Grand Saconnex, Geneva, Switzerland.

\section{Authors' contributions}

HSL conceived of the study, and participated in its design and drafted the manuscript. DKK carried out the microarray data analysis, the real time PCR, and helped to draft the manuscript. SHL performed the diets and disease challenge. DMB was involved in the experimental design and helped to draft the manuscript. All authors read and approved the final manuscript.

\section{Competing interests}

The authors declare that they have no competing interests.

\section{Published: 3 June 2011}

\section{References}

1. Lee SH, Lillehoj HS, Hong YH, Jang SI, Lillehoj EP, lonescu C, Mazuranok L, Bravo D: In vitro effects of plant and mushroom extracts on immunological function of chicken lymphocytes and macrophages. $\mathrm{Br}$ Poult Sci 2010, 51(2):213-221. 
2. Jamroz D, Wiliczkiewicz A, Wertelecki T, Orda J, Skorupinska J: Use of active substances of plant origin in chicken diets based on maize and locally grown cereals. Br Poult Sci 2005, 46(4):485-493.

3. De Vincenzi M, Stammati A, De Vincenzi A, Silano M: Constituents of aromatic plants: carvacrol. Fitoterapia 2004, 75(7-8):801-804.

4. Burt SA, Vlielander R, Haagsman HP, Veldhuizen EJ: Increase in activity of essential oil components carvacrol and thymol against Escherichia coli O157:H7 by addition of food stabilizers. J Food Prot 2005, 68(5):919-926.

5. Veldhuizen EJ, Tjeerdsma-van Bokhoven JL, Zweiltzer C, Burt SA, Haagsman HP: Structural requirements for the antimicrobial activity of carvacrol. J Agric Food Chem 2006, 54(5):1874-1879.

6. Burt SA, Fledderman MJ, Haagsman HP, van Knapen F, Veldhuizen EJ: Inhibition of Salmonella enterica serotype Enteritidis on agar and raw chicken by carvacrol vapour. Int J Food Microbiol 2007, 119(3):346-350.

7. Chang ST, Chen PF, Chang SC: Antibacterial activity of leaf essential oils and their constituents from Cinnamomum osmophloeum. J Ethnopharmacol 2001, 77(1):123-127.

8. Oboh G, Rocha JB: Hot Pepper (Capsicum spp.) protects brain from sodium nitroprusside- and quinolinic acid-induced oxidative stress in vitro. J Med Food 2008, 11(2):349-355.

9. Loizzo MR, Tundis R, Menichini F, Statti GA: Influence of ripening stage on health benefits properties of Capsicum annuum var. acuminatum L.: in vitro studies. J Med Food 2008, 11(1):184-189.

10. Tellez GI, Jaeger L, Dean CE, Corrier DE, DeLoach JR, Williams JD, Hargis BM: Effect of prolonged administration of dietary capsaicin on Salmonella enteritidis infection in leghorn chicks. Avian Dis 1993, 37(1):143-148.

11. McElroy AP, Manning JG, Jaeger LA, Taub M, Williams JD, Hargis BM: Effect of prolonged administration of dietary capsaicin on broiler growth and Salmonella enteritidis susceptibility. Avian Dis 1994, 38(2):329-333.

12. Kussmann M, Raymond F, Affolter M: OMICS-driven biomarker discovery in nutrition and health. J Biotechnol 2006, 124(4):758-787.

13. Chami F, Chami N, Bennis S, Trouillas J, Remmal A: Evaluation of carvacrol and eugenol as prophylaxis and treatment of vaginal candidiasis in an immunosuppressed rat model. J Antimicrob Chemother 2004, 54(5):909-914.

14. Kristinsson KG, Magnusdottir AB, Petersen $H$, Hermansson A: Effective treatment of experimental acute otitis media by application of volatile fluids into the ear canal. J Infect Dis 2005, 191(11):1876-1880.

15. Luna A, Labaque MC, Zygadlo JA, Marin RH: Effects of thymol and carvacrol feed supplementation on lipid oxidation in broiler meat. Poult Sci 89(2):366-370.

16. Kosar M, Demirci B, Demirci F, Baser KH: Effect of maturation on the composition and biological activity of the essential oil of a commercially important Satureja species from Turkey: Satureja cuneifolia Ten. (Lamiaceae). J Agric Food Chem 2008, 56(6):2260-2265.

17. Vinothini G, Nagini S: Correlation of xenobiotic-metabolizing enzymes, oxidative stress and NFkappaB signaling with histological grade and menopausal status in patients with adenocarcinoma of the breast. Clin Chim Acta 411(5-6):368-374.

18. Hernandez F, Madrid J, Garcia V, Orengo J, Megias MD: Influence of two plant extracts on broilers performance, digestibility, and digestive organ size. Poult Sci 2004, 83(2):169-174

19. Jamroz D, Wertelecki T, Houszka M, Kamel C: Influence of diet type on the inclusion of plant origin active substances on morphological and histochemical characteristics of the stomach and jejunum walls in chicken. J Anim Physiol Anim Nutr (Berl) 2006, 90(5-6):255-268.

20. Kim DK, Lillehoj HS, Lee SH, Jang SI, Bravo D: High-throughput gene expression analysis of intestinal intraepithelial lymphocytes after oral feeding of carvacrol, cinnamaldehyde, or Capsicum oleoresin. Poult Sci 89(1):68-81.

21. Rutten B, Gocke $E$ : The 'antimutagenic' effect of cinnamaldehyde is due to a transient growth inhibition. Mutat Res 1988, 201(1):97-105.

22. Lee SH, Lillehoj HS, Jang SI, Kim DK, lonescu C, Bravo D: Effect of Dietary Curcuma, Capsicum, and Lentinus, on Enhancing Local Immunity against Eimeria acervulina Infection. The Journal of Poultry Science 2010, 47:89-95.

23. Davis SJ, Ikemizu S, Wild MK, van der Merwe PA: CD2 and the nature of protein interactions mediating cell-cell recognition. Immunol Rev 1998, 163:217-236.

24. Ohnuma K, Munakata Y, Ishii T, Iwata S, Kobayashi S, Hosono O, Kawasaki H, Dang NH, Morimoto C: Soluble CD26/dipeptidyl peptidase IV induces T cell proliferation through CD86 up-regulation on APCs. J Immunol 2001, 167(12):6745-6755.

25. Panjwani NN, Popova L, Srivastava PK: Heat shock proteins gp96 and hsp70 activate the release of nitric oxide by APCs. J Immunol 2002, 168(6):2997-3003.

26. Panagiotou G, Nielsen J: Nutritional systems biology: definitions and approaches. Annu Rev Nutr 2009, 29:329-339.

27. Hong YH, Lillehoj HS, Lee SH, Dalloul RA, Lillehoj EP: Analysis of chicken cytokine and chemokine gene expression following Eimeria acervulina and Eimeria tenella infections. Vet Immunol Immunopathol 2006, 114(34):209-223.

28. Hong YH, Lillehoj HS, Lillehoj EP, Lee SH: Changes in immune-related gene expression and intestinal lymphocyte subpopulations following Eimeria maxima infection of chickens. Vet Immunol Immunopathol 2006, 114(3-4):259-272.

29. Min W, Lillehoj HS, Ashwell CM, van Tassell CP, Dalloul RA, Matukumalli LK, Han JY, Lillehoj EP: Expressed sequence tag analysis of Eimeriastimulated intestinal intraepithelial lymphocytes in chickens. Mol Biotechnol 2005, 30(2):143-150.

30. Min W, Lillehoj HS, Kim S, Zhu JJ, Beard H, Alkharouf N, Matthews BF: Profiling local gene expression changes associated with Eimeria maxima and Eimeria acervulina using CDNA microarray. Appl Microbiol Biotechnol 2003, 62(4):392-399.

31. McShane LM, Shih JH, Michalowska AM: Statistical issues in the design and analysis of gene expression microarray studies of animal models. $J$ Mammary Gland Biol Neoplasia 2003, 8(3):359-374.

32. Kim CH, Lillehoj HS, Bliss TW, Keeler CL Jr., Hong YH, Park DW, Yamage $M$, Min W, Lillehoj EP: Construction and application of an avian intestinal intraepithelial lymphocyte CDNA microarray (AVIELA) for gene expression profiling during Eimeria maxima infection. Vet Immunol Immunopathol 2008, 124(3-4):341-354.

doi:10.1186/1753-6561-5-S4-S34

Cite this article as: Lillehoj et al.: Effects of dietary plant-derived

phytonutrients on the genome-wide profiles and coccidiosis resistance in the broiler chickens. BMC Proceedings 2011 5(Suppl 4):S34.

\section{Submit your next manuscript to BioMed Central and take full advantage of:}

- Convenient online submission

- Thorough peer review

- No space constraints or color figure charges

- Immediate publication on acceptance

- Inclusion in PubMed, CAS, Scopus and Google Scholar

- Research which is freely available for redistribution

Submit your manuscript at www.biomedcentral.com/submit
C Biomed Central 